GRASAS Y ACEITES 70 (4)

October-December 2019, e331

ISSN-L: 0017-3495

https://doi.org/10.3989/gya.0825182

\title{
Crystallization kinetics of safflower and olive oils during low-temperature storage
}

\author{
M. Yoshida ${ }^{\mathrm{a}}$, Y. Miyagawa ${ }^{\mathrm{b}}$, H. Fujita ${ }^{\mathrm{b}}$ and S. Adachi ${ }^{\mathrm{b}, \varpi}$ \\ ${ }^{a}$ Division of Food Science and Biotechnology, Graduate School of Agriculture, Kyoto University, Sakyo-ku, Kyoto 606-8502, Japan. \\ ${ }^{b}$ Faculty of Bioenvironmental Science, Kyoto Gakuen University, Kameoka, Kyoto 621-8555, Japan. \\ Corresponding author: adachi-s@kyotogakuen.ac.jp
}

Submitted: 30 August 2018; Accepted: 23 January 2019; Published online: 22 July 2019

SUMMARY: The crystallization behaviors of safflower and olive oils were investigated according to changes in volume and transmitted light intensity during isothermal storage at low temperature. The changes between the oils were significantly different even though their fatty acid compositions were similar, with oleic acid accounting for more than $75 \%(\mathrm{w} / \mathrm{w})$ of the total oil. It was expected that minor components with high melting points would affect the crystallization behaviors of these oils. The crystallization processes of the oils were then analyzed using a kinetic model in which the oil crystallizes through two different processes. It is suggested that although the crystallization behaviors were apparently different, the crystallization mechanisms of these oils are essentially the same.

KEYWORDS: Crystallization; Kinetic; Olive oil; Safflower oil

RESUMEN: Cinéticas de cristalización de aceites de cártamo y oliva durante el almacenamiento a baja temperatura. Se estudiaron los comportamientos durante la cristalización de aceites de cártamo y oliva en función de los cambios en el volumen y la intensidad de la luz transmitida durante el almacenamiento isotérmico a baja temperatura. Los cambios fueron significativamente diferentes entre los dos aceites, aunque su composición en ácidos grasos era similar, con el ácido oleico en una proporción superior al 75\% (p/p). Se esperaba que los componentes menores con altos puntos de fusión afectarían a los comportamientos de cristalización de estos aceites. Los procesos de cristalización de los aceites se analizaron utilizando un modelo cinético en el que el aceite cristaliza a través de dos procesos diferentes. Se sugiere que, aunque los comportamientos de cristalización fueron aparentemente diferentes, los mecanismos de cristalización de estos aceites serían esencialmente los mismos.

PALABRAS CLAVE: Aceite de cártamo; Aceite de oliva; Cinética; Cristalización

ORCID ID: Yoshida M https://orcid.org/0000-0002-7309-6889, Miyagawa Y https://orcid.org/0000-0002-4251-526X, Fujita H https://orcid.org/0000-0002-5281-1898, Adachi S https://orcid.org/0000-0001-7417-6146

Citation/Cómo citar este artículo: Yoshida M, Miyagawa Y, Fujita H, Adachi S. 2019. Crystallization kinetics of safflower and olive oils during low-temperature storage. Grasas Aceites 70 (4), e331. https://doi.org/10.3989/gya.0825182

Copyright: (02019 CSIC. This is an open-access article distributed under the terms of the Creative Commons Attribution 4.0 International (CC BY 4.0) License. 


\section{INTRODUCTION}

Vegetable oils are multi-component systems containing various triacylglycerols (TAGs), in which three fatty acid molecules are ester-bond to a glycerol molecule (Himawan, Starov, and Stapley, 2006). Depending on the oil type, it can contain TAGs with largely different melting points. The fractionation of oils having different melting points has been performed on an industrial scale. For an efficient fractionation of oils, it is necessary to reasonably control the size and form of the crystals, which are affected by the cooling conditions (Abeshima, 1998; Hamm, 1995). Because the crystals affect the physical properties and appearance of foods, the control of the crystal size, shape, and polymorph is important for producing food with high quality (RincónCardona et al., 2013; Himawan et al., 2006). Furthermore, owing to the diversification of trends in food consumption, the physical properties of required oils and fats are also diversified (Fujiwara et al., 1972). The composition of TAGs and constituent fatty acids influences the crystallization behavior (Abeshima, 1998). For food distribution and preservation, it is important to predict the time at which crystallization begins or polymorphic transition occurs during storage. Lipid crystallization may cause oil-water separation in emulsified foods (Coupland, 2002; Rousseau, 2000). Differences in polymorphism may also affect the oxidation behavior of lipids (Calligaris et al., 2006).

The crystallization behavior of oils with high melting points, such as palm oil and cacao butter, has been investigated as well as the effect of adding other oils and fats or talc (de Oliveira et al., 2015; Quast et al., 2013; Yoshikawa et al., 2016). The crystallization behavior of vegetable oils with low melting points, sunflower (Calligaris et al., 2008) and olive oils (Barba et al., 2013; Bayés-García et al., 2017), has also been investigated. Studies on crystallization polymorphism (Barba et al., 2013; BayésGarcía et al., 2017), and the effects of oxidation of the oil (Calligaris et al., 2006, Chiavaro et al., 2012) and TAG compositions (Bayés-García et al., 2017) on the crystallization behaviors have been reported, especially for olive oil. However, studies on the crystallization behavior of oils with low melting points are far fewer compared to those of oils with high melting points and in many cases this behavior remains unclear.

We previously studied the crystallization behavior of rapeseed oil, which is a vegetable oil with a low melting point, particularly the time required for crystallization during isothermal storage, or the induction period of crystallization. In that study, stress measurement, temperature measurement, and differential scanning calorimetry (DSC) analysis revealed that several hours to half a day were required for complete crystallization during the isothermal storage of rapeseed oil at low temperatures (Miyagawa et al., 2015; Miyagawa et al., 2016). $\mathrm{X}$-ray structural analysis showed minute structural changes during the induction period for crystallization and the crystalline polymorphism after crystallization (Miyagawa et al., 2017). Although these methods are useful for identifying the details of phenomena occurring during the crystallization process, they are not applicable to continuous measurement for the same sample over a long period of time. Moreover, it is difficult to quantitatively interpret the results.

In addition to the methods described above, the crystallization behavior of oils can also be measured by dilatometry (Bailey and Kraemer, 1944; Fulton et al., 1954), turbidity measurement, transmitted light intensity measurement (Wright et al., 2000), microscopic observation (Kellens et al., 1992), and pulsed nuclear magnetic resonance (pNMR) spectroscopy (Campbell et al., 2004). Dilatometry is a classic, useful method for examining the crystallization behavior of oils. This method provides information about volumetric change in the bulk oil, which is a crystallization ratio, and crystal structure such as polymorphism (Bailey et al., 1944). This contrasts with DSC and X-ray structural analyses, which provide thermal and microscopic information. In addition, dilatometry is advantageous for a non-destructive measurement of the same sample over a long period. Volumetric dilatometry is a method for measuring volumetric changes in the oil using a dilatometer consisting of a bulb filled with oil and a capillary filled with an immiscible liquid. Because the filling liquid must not be evaporated or frozen during the measurement, mercury has frequently been used in dilatometry for oils. However, in recent years, the adverse safety and environmental aspects of using mercury have made its use largely discontinued. Because it is difficult to find an alternative appropriate filling, the dilatometry technique for measuring the crystallization behavior of oil has also been discontinued. We showed previously that the crystallization behavior of rapeseed oil can be accurately measured by dilatometry when a using 30\% (w/w) $\mathrm{CaCl}_{2}$ solution (brine) as filling liquid (Miyagawa, Yoshida, Nakagawa, Adachi, 2018). The measurement of turbidity or transmitted light intensity is an effective method for observing microscopic changes occurring in the crystallization process (Wright, Narine, Marangoni, 2000) as well as pNMR. The measurement of transmitted light intensity is easily conducted and is more sensitive than pNMR spectroscopy (Wright et al., 2000). We previously applied the transmitted light intensity measurement method to monitor the crystallization of rapeseed oil during its isothermal storage (Miyagawa et al., 2018).

The Avrami or Kolmogorov-Johnson-MehlAvrami (KJMA) model (Avrami, 1940) has been most 
frequently used for describing the crystallization behavior of oil. In addition, the nucleation rate of TAGs in vegetable oil is expressed by the Fisher-Turnbull equation (MacNaughtan et al., 2006; Turnbull and Fisher, 1949). However, these methods cannot be used to sufficiently express or analyze the crystallization process which includes the induction period. In this context, we previously proposed a kinetic model for the crystallization of rapeseed oil during isothermal storage at low temperatures (Miyagawa et al., 2018).

In the present study, the crystallization behaviors of safflower and olive oils were evaluated in the temperature ranges of -10 to $-20^{\circ} \mathrm{C}$ and -5 to $-17^{\circ} \mathrm{C}$, respectively, using dilatometry and transmitted light intensity measurement. The changes in volume were analyzed by using our previous model to evaluate the rate constants for the crystallization of the oils.

\section{MATERIALS AND METHODS}

\subsection{Materials}

The first-grade safflower oil, research-grade olive oil, special-grade sodium sulfate, and $28 \%$ sodium methoxide in methanol were purchased from Fujifilm Wako Pure Chemical Corp., Osaka, Japan. Special-grade calcium chloride was purchased from Nacalai Tesque, Kyoto, Japan.

\subsection{Fatty acid composition}

Approximately $100 \mu \mathrm{L}$ safflower or olive oil were mixed with $3 \mathrm{~mL}$ methanol and $0.8 \mathrm{~mL} 28 \%$ sodium methoxide in methanol, and the mixture was heated at $75{ }^{\circ} \mathrm{C}$ for $15 \mathrm{~min}$ using an aluminum block thermostat (Dry ThermoUnit, DTU$1 \mathrm{CN}$, Taitec, Saitama, Japan). After allowing the mixture to cool to room temperature, $3 \mathrm{~mL}$ hexane were added, and the mixture was stirred. $2 \mathrm{~mL}$ distilled water were then added, and the mixture was stirred again. Approximately $1 \mathrm{~mL}$ of the hexane layer was removed, and a sufficient amount of anhydrous sodium sulfate was added to dehydrate the hexane solution. The dehydrated hexane solution was centrifuged at $10,000 \mathrm{rpm}$ for $3 \mathrm{~min}$ using an MC-150 centrifuge (Tomy Seiko, Tokyo, Japan), and the upper layer was analyzed by gas chromatography (GC-2014, Shimadzu Corp., Kyoto) with a DB-23 capillary column (Agilent Technologies, Tokyo) and flame ionization detector to determine the fatty acid composition of the oil. The injector and detector temperatures were set at $245^{\circ} \mathrm{C}$ and $250{ }^{\circ} \mathrm{C}$, respectively. The column temperature was maintained at $150{ }^{\circ} \mathrm{C}$ for $0.5 \mathrm{~min}$ and raised gradually to $170^{\circ} \mathrm{C}$ at $4{ }^{\circ} \mathrm{C} / \mathrm{min}, 195^{\circ} \mathrm{C}$ at $5^{\circ} \mathrm{C} / \mathrm{min}$, and $215^{\circ} \mathrm{C}$ at $10^{\circ} \mathrm{C} / \mathrm{min}$ before being held at $215^{\circ} \mathrm{C}$ for $5 \mathrm{~min}$. The composition of each oil is shown by the mean and standard deviation of triplicate analyses.

\subsection{Volumetric measurement}

The densities of $30 \%(\mathrm{w} / \mathrm{w}) \mathrm{CaCl}_{2}$ (designated as brine), safflower oil, and olive oil at $25^{\circ} \mathrm{C}$ were determined by pycnometry to be $1.2780 \pm 0.0009$, $0.9098 \pm 0.0005$, and $0.9094 \pm 0.0004 \mathrm{~g} / \mathrm{mL}$, respectively, which are the means \pm standard deviation of three measurements.

The dilatometric apparatus employed and the method used to measure the volumetric change in the oil were the same as those used in our previous study (Miyagawa et al., 2018). Briefly, a calibration curve related the storage temperature, $\theta\left({ }^{\circ} \mathrm{C}\right)$ and the volumetric change of the brine, $X_{\text {brine }}(\mathrm{mL} / \mathrm{g})$ was prepared from the brine. The calibration curve was linear with a correlation coefficient $R^{2}$ of 0.9988 and is expressed by

$$
X_{\text {brine }}=(\theta-30) / 3218(-40 \leq \theta \leq 30)
$$

Prior to use, the safflower and olive oils were degassed as follows. The safflower oil was frozen at $-80^{\circ} \mathrm{C}$ for $1 \mathrm{~h}$ and degassed under reduced pressure for $1 \mathrm{~h}$ during the thawing process. The oil was frozen again at $-80^{\circ} \mathrm{C}$ for $1 \mathrm{~h}$ and degassed under reduced pressure at room temperature overnight. The olive oil was frozen at $-80^{\circ} \mathrm{C}$ for $2 \mathrm{~h}$ and degassed under reduced pressure at room temperature overnight.

$50 \mathrm{~g}$ of the degassed safflower or olive oil were precisely weighed and placed in the bulb portion of the dilatometer and stored in a temperaturecontrolled chamber at $-25^{\circ} \mathrm{C}$ or $-30{ }^{\circ} \mathrm{C}$ for $30 \mathrm{~min}$ to be frozen. Approximately $60 \mathrm{~g}$ of the brine was layered onto the frozen oil, and the oil was then thawed. The dilatometer was allowed to stand for $2 \mathrm{~h}$ in a temperature-controlled chamber at $30^{\circ} \mathrm{C}$. It was then cooled to a specific temperature at a temperature-descending rate of $0.5^{\circ} \mathrm{C} / \mathrm{min}$ and kept at the specific temperature. The sum of volumetric changes in the oil and the brine, $V_{\text {total }}$, from the initial temperature set point of $30{ }^{\circ} \mathrm{C}$ were recorded every $10 \mathrm{~min}$. The volumetric change in the oil from the initial temperature set point, $X_{\text {oil }}(\mathrm{mL} / \mathrm{g})$, was calculated using Eq. (2):

$$
X_{\text {oil }}=\left(V_{\text {total }}-X_{\text {brine }} W_{\text {brine }}\right) / W_{\text {oil }}
$$

where $W_{\text {brine }}$ and $W_{\text {oil }}$ are weights of the brine and the oil, respectively.

The time from the start of isothermal storage to the time at which the volume began to change was defined as the induction period for crystallization. The point at which the derivative of the $X_{\text {oil }}$ with respect to time began to change was defined as the time at which the volume began to change. Measurements were performed in triplicate for the olive oil stored at $-7^{\circ} \mathrm{C}$ and once for other cases.

When safflower oil was stored at $-15{ }^{\circ} \mathrm{C}$, the change in temperature was measured every $5 \mathrm{~min}$ by 
using a K-type thermocouple installed in the center of the bulb.

\subsection{Measurement of transmitted light intensity}

The measurement was conducted in the same way as that reported in our previous study (Miyagawa et al., 2018). Briefly, the degassed oil was placed in a glass cuvette with an optical path length of $1 \mathrm{~cm}$ and frozen. After thawing, the intensity of the transmitted light was measured in the range of 360 to $830 \mathrm{~nm}$ by using an apparatus consisting of a tungsten light source (LS-1, Ocean Optics, Florida, USA) and a spectroscope (USB2000+UV-VIS-ES, Ocean Optics). The light intensity at $600 \mathrm{~nm}$ over 150 counts was recorded. Measurements were performed in triplicate for the olive oil stored at $-7^{\circ} \mathrm{C}$ and once for other cases.

\section{RESULTS AND DISCUSSION}

\subsection{Fatty acid composition}

Table 1 shows the fatty acid compositions of the safflower and olive oils used to measure the changes in volume and transmitted light intensity during storage at low temperatures. The main component of both the safflower and olive oils was oleic acid, at about $80 \%$ and $75 \%$, respectively. The second most common components were linoleic acid for safflower oil and palmitic acid for olive oil, at about $13 \%$ and $12 \%$, respectively.

\subsection{Changes in volume and transmitted light intensity of safflower oil}

The safflower oil was stored at $-10,-12,-15,-17$ and $-20^{\circ} \mathrm{C}$, and the changes in its volume and transmitted light intensity at $600 \mathrm{~nm}$ were measured with time (Figure 1). As with the change in the volume of rapeseed oil reported in our previous study (Miyagawa et al., 2018), the change in the volume of safflower oil progressed in three stages. In the first stage, the volume decreased in proportion to a decrease in temperature (cooling process). In the second stage, the volume was hardly changed at a constant temperature (induction period for crystallization). In the third stage, the volume decreased even at constant temperature.

The changes in volume and temperature were simultaneously measured for safflower oil stored at $-15{ }^{\circ} \mathrm{C}$ (Figure 2). The volume decrease and heat generation occurred simultaneously. This fact indicates that the heat generation was ascribed to a large structural change accompanying the change in volume, which describes crystallization.

Higher storage temperature was directly proportional to a remarkably longer induction period (Figure 3). The relationship between the storage
TABLE 1. Fatty acid compositions of safflower and olive oils

\begin{tabular}{lcr}
\hline Fatty acid $(\% \mathbf{~ ( w / w ) ) ~}$ & Safflower oil & Olive oil \\
\hline Palmitic acid & $4.5 \pm 0.1$ & $12.2 \pm 0.2$ \\
Stearic acid & $1.9 \pm 0.1$ & $2.4 \pm 0.4$ \\
Oleic acid & $79.7 \pm 0.1$ & $74.6 \pm 0.3$ \\
Linoleic acid & $12.9 \pm 0.1$ & $8.5 \pm 0.1$ \\
Linolenic acid & $0.1 \pm 0.0$ & $0.6 \pm 0.0$ \\
Arachidic acid & $0.4 \pm 0.0$ & $0.4 \pm 0.0$ \\
Others & $0.6 \pm 0.0$ & $1.3 \pm 0.0$
\end{tabular}

The values represent the mean \pm standard deviation $(n=3)$.
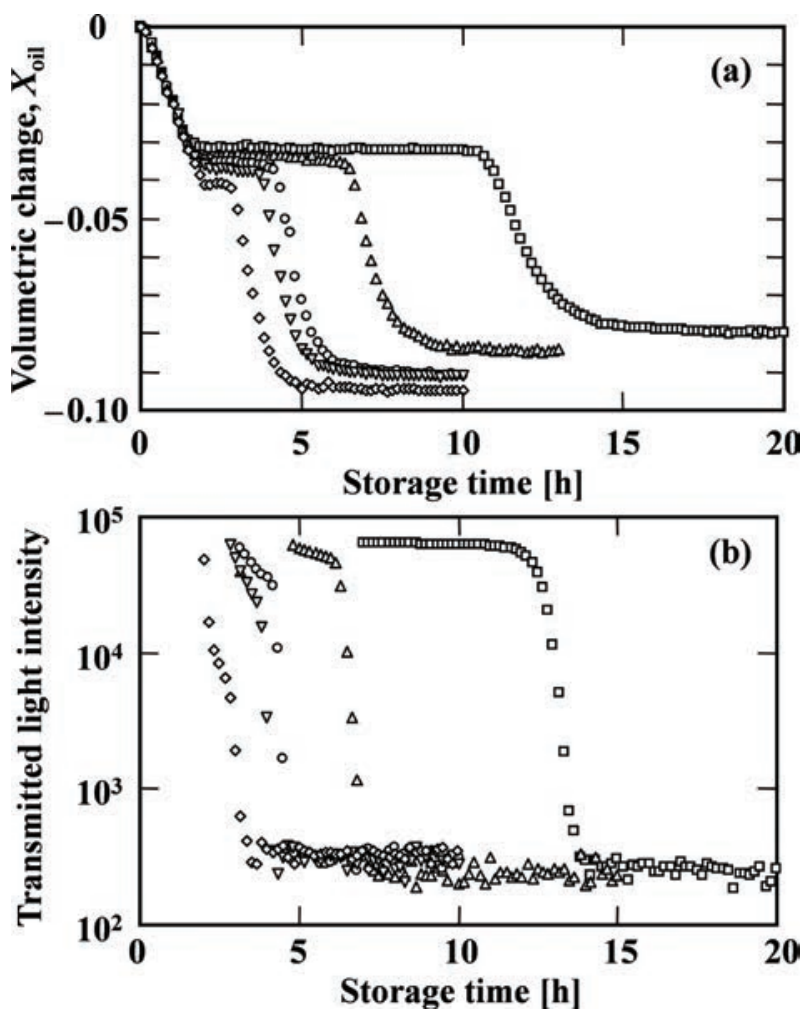

Figure 1. Changes in (a) volume and (b) transmitted light intensity of safflower oil at various temperatures of $-10^{\circ} \mathrm{C}$ $(\square),-12^{\circ} \mathrm{C}(\Delta),-15^{\circ} \mathrm{C}(O),-17^{\circ} \mathrm{C}(\nabla)$, and $-20^{\circ} \mathrm{C}(\diamond)$. The volume and transmitted light of the oil were measured once at each temperature.

temperature and the induction period for safflower oil was consistent with that of our previous study (Miyagawa et al, 2019).

At the beginning of the measurement, the transmitted light intensity was too large to be detected and gradually decreased during the subsequent induction period. A lower storage temperature related to a greater decrease in transmitted light intensity and in the rate of decrease.

The transmitted light intensity of the oil stored at $-10{ }^{\circ} \mathrm{C}$ sharply decreased after the volume began to decrease, whereas the decrease in volume and the sharp decrease in transmitted light intensity 
occurred almost simultaneously for the oil stored at $-12{ }^{\circ} \mathrm{C}$. This fact suggests that the process of macroscopic crystallization development might be different at $-10^{\circ} \mathrm{C}$ and $-12^{\circ} \mathrm{C}$ or at lower temperatures.

In the process of rapeseed oil crystallization, a phenomenon was observed in which the transmitted light intensity increased once during the induction period. This increase suggests that a melt-mediated transition occurred in which the rapeseed oil in a nearly solid state changed to a liquid state and then crystallized (Miyagawa et al., 2018).

The safflower oil did not exhibit an increase in transmitted light intensity during the induction period. This fact suggests that the safflower oil

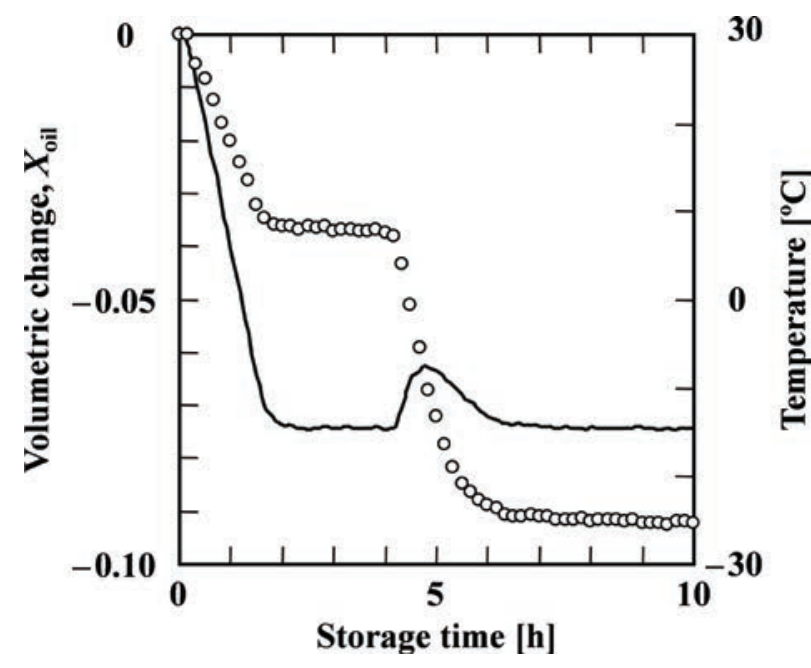

FIGURE 2. Volumetric and temperature changes in safflower oil during storage at $-15^{\circ} \mathrm{C}$.

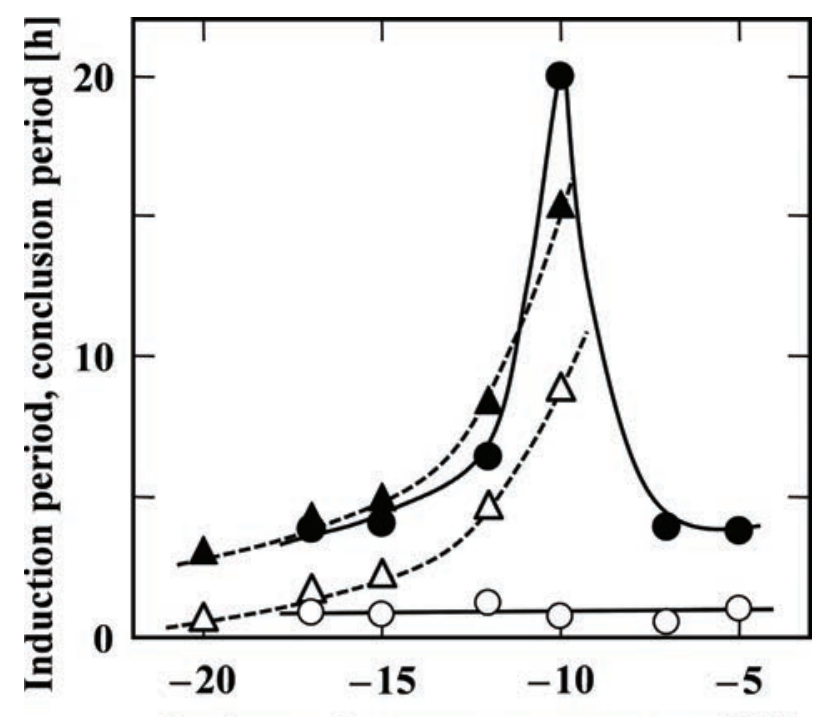

Isothermal storage temperature $\left[{ }^{\circ} \mathrm{C}\right]$

FiguRE 3. Effects of storage temperature on the induction period (open symbols) and the conclusion period (closed symbols) of safflower oil $(\triangle, \boldsymbol{\Lambda})$ and olive oil $(\mathrm{O}, \boldsymbol{\bullet})$. crystallized by a mechanism different from meltmediated transition or that the change accompanying the transition was very small.

\subsection{Changes in volume and transmitted light intensity of olive oil}

Figure 4 shows the transient changes in volume and in the transmitted light intensity of olive oil stored at $-5,-7,-10,-12,-15$, or $-17^{\circ} \mathrm{C}$. Compared with that for safflower oil, olive oil showed a large change in volume during the induction period. Moreover, this tendency was more pronounced at a lower storage temperature. The relationship between the storage temperature and induction period of the olive oil was different from that of safflower oil. That is, the induction period of olive oil did not decrease monotonically with a decrease in storage temperature and was the longest when stored at a specific temperature of $-10^{\circ} \mathrm{C}$.

The changes in volume and transmitted light intensity of olive oil varied greatly at $-10{ }^{\circ} \mathrm{C}$, as did the induction period. The volumetric change in olive oil after crystallization was -0.08 to $-0.09 \mathrm{~mL} / \mathrm{g}$ at -10 ${ }^{\circ} \mathrm{C}$ or lower temperatures. This volumetric change is
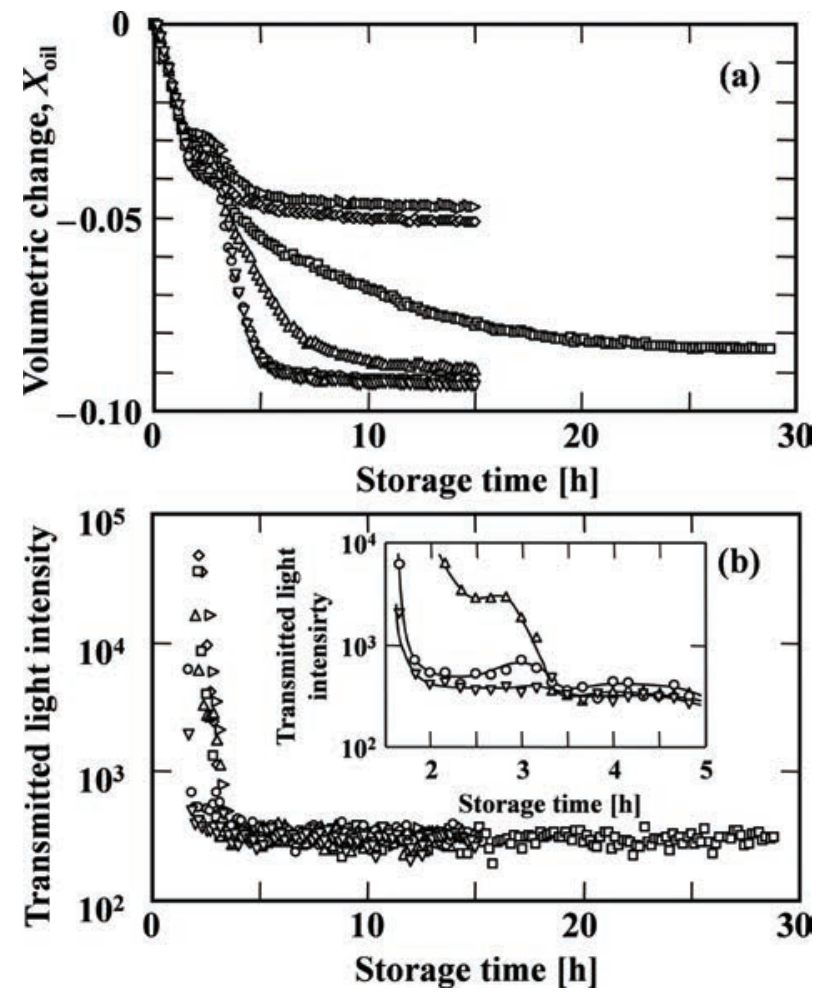

FiguRE 4. Changes in (a) volume and (b) transmitted light intensity in olive oil at various temperatures of $-5^{\circ} \mathrm{C}(\triangleright),-7{ }^{\circ} \mathrm{C}(\diamond),-10^{\circ} \mathrm{C}(\square),-12^{\circ} \mathrm{C}(\triangle),-15^{\circ} \mathrm{C}(\mathrm{O})$, and $-17^{\circ} \mathrm{C}(\nabla)$. The volume and transmitted light of the oil stored at $-7{ }^{\circ} \mathrm{C}$ were measured in triplicate, but only mean values are shown to avoid complication of the graph. Measurements were performed once for other cases. 
almost the same as those of safflower and rapeseed oils, at -0.07 to $-0.10 \mathrm{~mL} / \mathrm{g}$ (Miyagawa et al., 2018). The volumetric changes at $-5^{\circ} \mathrm{C}$ and $-7{ }^{\circ} \mathrm{C}$ were both about $-0.05 \mathrm{~mL} / \mathrm{g}$, which is greater than those at other temperatures.

Figure 5 shows the density of olive oil at various temperatures, which was calculated from the volumetric change. The densities at $-5^{\circ} \mathrm{C}$ and $-7{ }^{\circ} \mathrm{C}$ are almost the same as that of liquid. The olive oil kept at $-5^{\circ} \mathrm{C}$ and $-7{ }^{\circ} \mathrm{C}$ appeared to be partially crystallized. However, the olive oil was fully crystallized at $-10{ }^{\circ} \mathrm{C}$ and appeared to be uniform, and no phase separation was observed macroscopically. Oil in a liquid or liquid-like state appeared to exist in the void of the solid crystals.

The duration from the start of the isothermal storage to the end of the volumetric decrease of the oil stored at $-10^{\circ} \mathrm{C}$, which is designated as the conclusion period of crystallization, was significantly longer than the conclusion periods of oils stored at other temperatures.

Unlike that of safflower oil, the volume of olive oil stored at $-10^{\circ} \mathrm{C}$ did not decrease smoothly but exhibited a step-wise change that was significant between 5 and $15 \mathrm{~h}$ of storage time. This change suggests that crystals of different structures were generated in a step-wise fashion or that the structures of the crystals gradually changed.

The transmitted light intensity of the olive oil showed different behaviors at temperatures higher and lower than $-10^{\circ} \mathrm{C}$ as well as volumetric change. At $-10{ }^{\circ} \mathrm{C}$ or higher, the transmitted light intensity of the olive oil greatly decreased when its volume

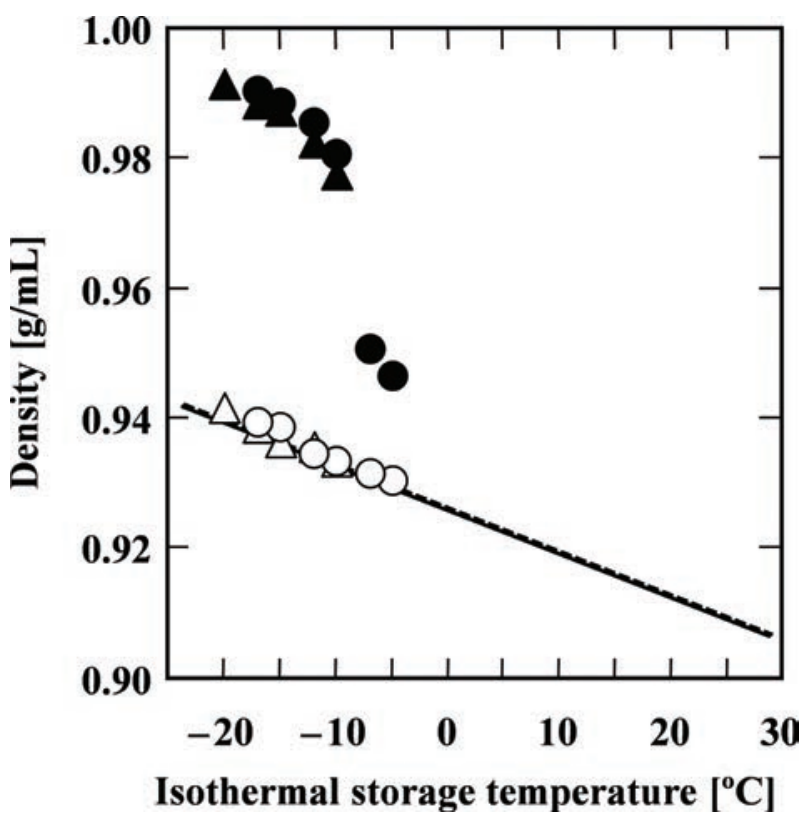

FIGURE 5. Densities of safflower $(\Delta, \boldsymbol{\Delta})$ and olive oils $(\bigcirc, \bullet)$ before crystallization (open symbols) and after crystallization (closed symbols). began to decrease. The transmitted light intensity of the olive oil stored at $-12,-15$, and $-17{ }^{\circ} \mathrm{C}$ did not decrease monotonically but temporarily increased just before crystallization. This temporary increase can be attributed to melt-mediated transition. Therefore, the transition would have occurred at below $-12{ }^{\circ} \mathrm{C}$. The melt-mediated transition is likely to occur at relatively high temperatures. This means that the transition is more likely to occur when the difference between the storage temperature and the melting point of TAGs to crystallize is smaller (Miyagawa et al., 2018). However, it is interesting to note that the olive oil underwent the transition at $-12{ }^{\circ} \mathrm{C}$ or lower rather than at $-10^{\circ} \mathrm{C}$ or higher.

The aforementioned density suggests that only some TAGs crystallized at $-5^{\circ} \mathrm{C}$ and $-7{ }^{\circ} \mathrm{C}$. The crystallized TAGs were presumed to be those with high melting points and likely included palmitic acid or stearic acid, such as LPP, SOS, POS, and $\mathrm{PPP}$, for which $\mathrm{L}, \mathrm{O}, \mathrm{S}$, and $\mathrm{P}$ represent linoleic, oleic, stearic, and palmitic acids, respectively. The content of each TAG was less than $1 \%$ in oilve oil, but more than those in safflower and rapeseed oils (Totani, 2012). It was considered that all the TAGs, including those with low melting points such as OOO, OOP, and LOO, crystallized at $-10{ }^{\circ} \mathrm{C}$ or lower. These TAGs were the main three components of the olive oil in decending order (Bayés-García et al., 2017; Totani, 2012). The crystallization of TAGs with high melting points would occur at temperatures higher than $-10^{\circ} \mathrm{C}$, and the crystallization of all TAGs would occur at $-10{ }^{\circ} \mathrm{C}$ or lower. When only TAGs with high melting points crystallized, the melt-mediated transition hardly occurred because $-10^{\circ} \mathrm{C}$ is a relatively low temperature. When all of the TAGs crystallized, the meltmediated transition would have occurred because $-12^{\circ} \mathrm{C}$ is a relatively high temperature. The temporarily increased transmitted light intensity at the temperature range of $-12{ }^{\circ} \mathrm{C}$ to $-17^{\circ} \mathrm{C}$ was larger at the higher storage temperature. The oil in which the melt-mediated transition occurred appeared to be in the most liquid-like state at $-12{ }^{\circ} \mathrm{C}$. This also indicates that $-12^{\circ} \mathrm{C}$ is a relatively high temperature for the crystallization of the oil.

\subsection{Changes in density before and after crystallization}

In our previous study (Miyagawa et al., 2018), we showed that the density of liquid rapeseed oil immediately after the commencement of isothermal storage, in which no crystal had formed, was proportional to the temperature even though the oil crystallized after a certain period. Timms (1985) reported that the proportionality constant is $6.8 \times 10^{-4} \mathrm{~mL} / \mathrm{g} \cdot{ }^{\circ} \mathrm{C}$, regardless of the oil type. According to the Timms formula and using the densities measured at $25^{\circ} \mathrm{C}$, the relationships between 
density $\rho(\mathrm{g} / \mathrm{mL})$ and storage temperature $T\left({ }^{\circ} \mathrm{C}\right)$ for the safflower and olive oils are given by Eqs. (3) and (4), respectively.

$$
\begin{aligned}
& \rho=6.8^{\prime} 10^{-4} \mathrm{~T}+0.9268 \\
& \rho=6.8^{\prime} 10^{-4} \mathrm{~T}+0.9264
\end{aligned}
$$

For each oil, the density $\rho_{\text {iso }}$ at the beginning of isothermal storage (i.e., at the end of the cooling process) and the density $\rho_{\text {cry }}$ after crystallization were estimated (Figure 5). The determination coefficients $R^{2}$ of Eqs. (3) and (4) for $\rho_{\text {iso }}$ of safflower and olive oils were 0.950 and 0.948 , respectively, suggesting that no crystals were formed in either oil during the cooling process.

The $\rho_{\text {cry }}$ values of the safflower and olive oils were larger at the lower storage temperature and showed convex shapes against the temperature. The density of crystals is closely related to the packing structure of the TAG molecules (Himawan et al., 2006). The most abundant TAG in both the safflower and olive oils is triolein (Bayés-García et al., 2017; Totani, 2012). Because the TAG molecules that were present most frequently were common to both the oils, it appears that they showed a similar temperature dependency of density. Olive oil contains more fatty acids with high melting points, palmitic acid, and stearic acid than safflower oil (Table 1); thus, olive oil would have more TAGs with high melting points. It was reported that some TAGs containing palmitic and stearic acids were more rich in olive oil than in safflower oil as mentioned in section 3.3 (Totani, 2012). The melting point of olive oil containing more components with high melting points is thought to be comprehensively higher than that of safflower oil (Miyagawa et al., 2019). Therefore, olive oil crystallized at a relatively lower temperature would have higher density.

\subsection{Crystallization kinetics}

Based on the kinetic model (Miyagawa et al., 2018) shown in Figure 6, the changes in the volume of safflower and olive oils that occurred during the isothermal storage were analyzed. The kinetic model effectively represented the normalized volumetric change during the crystallization process of rapeseed oil including the induction period, which is defined by Eq. (5) (Miyagawa et al., 2018):

$$
V_{\text {cry }}=\left(X_{\mathrm{oil}, 0}-X_{\mathrm{oil},}\right) /\left(X_{\mathrm{oil}, \infty}-X_{\mathrm{oil}, 0}\right)
$$

where $X_{\mathrm{oil}}$ is the volumetric change at any storage time, and $X_{\text {oil, }, 0}$ and $X_{\text {oil,o }}$ are the volumetric changes that occur from the beginning of cooling at $30^{\circ} \mathrm{C}$ to the starting point of isothermal storage at a specific temperature and from the beginning of cooling at $30{ }^{\circ} \mathrm{C}$ to the end of crystallization, respectively.

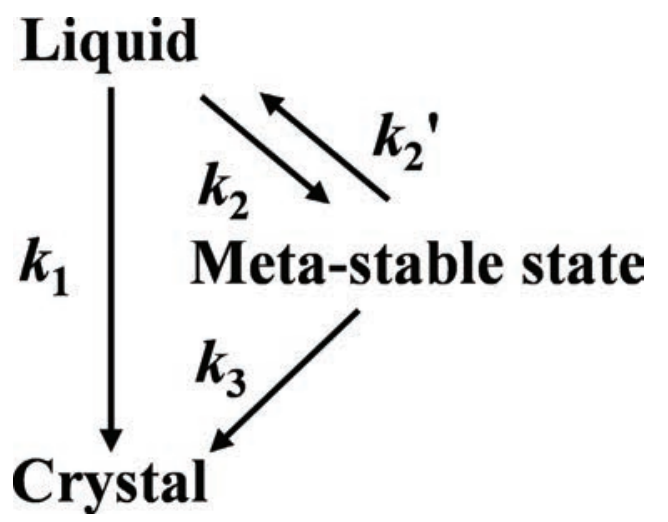

FIGURE 6. Kinetic model for crystallization of rapeseed oil.

The model assumes two processes for crystallization and consists of four steps. All of the steps are considered to be expressed by first-order kinetics. In one process, liquid oil crystallizes directly, with a rate constant $k_{1}$; in the other, oil crystallizes through an intermediate state (meta-stable state). In step 2 , liquid oil changes to the meta-stable state with a rate constant $k_{2}$. Step $2^{\prime}$ with rate constant $k_{2}^{\prime}$ is the reverse reaction of step 2 . Steps 2 and $2^{\prime}$ represent the melt-mediated transition. In step 3 , with a rate constant $k_{3}$, crystals generated earlier promote autocatalytical change from the meta-stable to crystal state.

The analysis of the crystallization behavior of the safflower and olive oils showed that the $k_{2}^{\prime}$ value was very small or zero at the storage temperature at which no increase in transmitted light intensity was observed. The $k_{2}{ }^{\prime}$ values for the safflower oils stored at all temperatures and for the olive oil stored at $-5^{\circ} \mathrm{C}$ and $-7^{\circ} \mathrm{C}$ were regarded as zero.

Figure 7 shows the changes in the volume of safflower and olive oils during their isothermal storage. The root mean squared errors (RMSE), which are defined by Eq. (6), were in the range of $1.30 \times 10^{-2}$ to $2.78 \times 10^{-2}$, and the model effectively expressed the changes in volume of both oils during storage at any temperature:

$$
R M S E=\sqrt{\left(V_{\mathrm{cal}}-V_{\mathrm{obs}}\right)^{2} / n},
$$

where $V_{\text {obs }}$ and $V_{\text {cal }}$ are the experimentally observed $V_{\text {cry }}$ value and that calculated according to the model, respectively.

Figure 8 shows the Arrhenius plots for the rate constants $k_{1}, k_{2}, k_{2}^{\prime}$, and $k_{3}$ for safflower and olive oils. The $k_{1}, k_{2}$, and $k_{3}$ values for safflower oil increased with a decrease in temperature. This fact effectively reflects that a lower storage temperature relates to a shorter induction period of crystallization. The activation energy for $k_{1}$ was about $-550 \mathrm{~kJ} / \mathrm{mol}$. This large value of activation energy indicates that the crystallization process of 

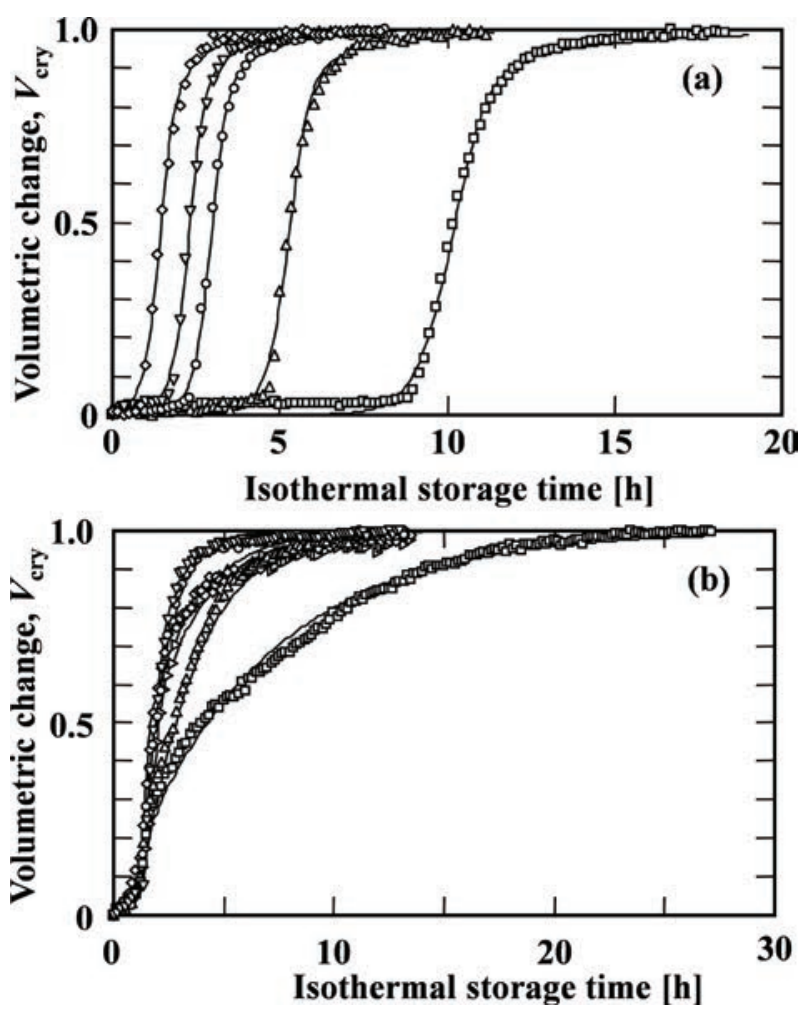

Figure 7. Temperature dependence of the rate constants for the crystallization of (a) safflower and (b) olive oils: $k_{1}$, $(\mathrm{O}), k_{2}(\Delta), k_{2}^{\prime}(\nabla), k_{3}(\square)$. The broken and solid lines are the densities of safflower and olive oils, which were calculated according to Eqs. (3) and (4), respectively.

safflower oil through step 1 is sensitive to temperature change.

The temperature dependencies of the rate constants for olive oil changed at $-10{ }^{\circ} \mathrm{C}$. As the temperature decreased, the $k_{1}$ value increased between $-5^{\circ} \mathrm{C}$ and $-10^{\circ} \mathrm{C}$ but decreased between $-10{ }^{\circ} \mathrm{C}$ and $-17^{\circ} \mathrm{C}$. As with the safflower oil, the $k_{2}$ value increased slightly with a decrease in storage temperature. The $k_{2}^{\prime}$ value was 0 at $-5{ }^{\circ} \mathrm{C}$ and $-7{ }^{\circ} \mathrm{C}$, as described above, and decreased between $-10{ }^{\circ} \mathrm{C}$ and $-17^{\circ} \mathrm{C}$ with a decrease in temperature. The $k_{3}$ value was 0 at $-10^{\circ} \mathrm{C}$, and those at other temperatures were almost the same.

From the temperature dependencies of the rate constants, the crystallization mechanism of olive oil was inferred as follows. At $-5^{\circ} \mathrm{C}$ and $-7{ }^{\circ} \mathrm{C}$, no melt-mediated transition occurred, and crystallization proceeded in parallel by direct change from liquid to crystal (step 1) and by autocatalytic change from meta-stable to crystal states (step 3). On the contrary, at $-10{ }^{\circ} \mathrm{C}$, the oil in the meta-stable state changed to a liquid state through melt-mediated transition (steps 2 and 2'), and the liquid oil then crystallized directly through step 1 . Therefore, it is presumed that step 3 did not proceed. This presumption agrees with our previous consideration (Miyagawa et al., 2018) such that step 3 proceeds when step $2^{\prime}$ hardly proceeds.
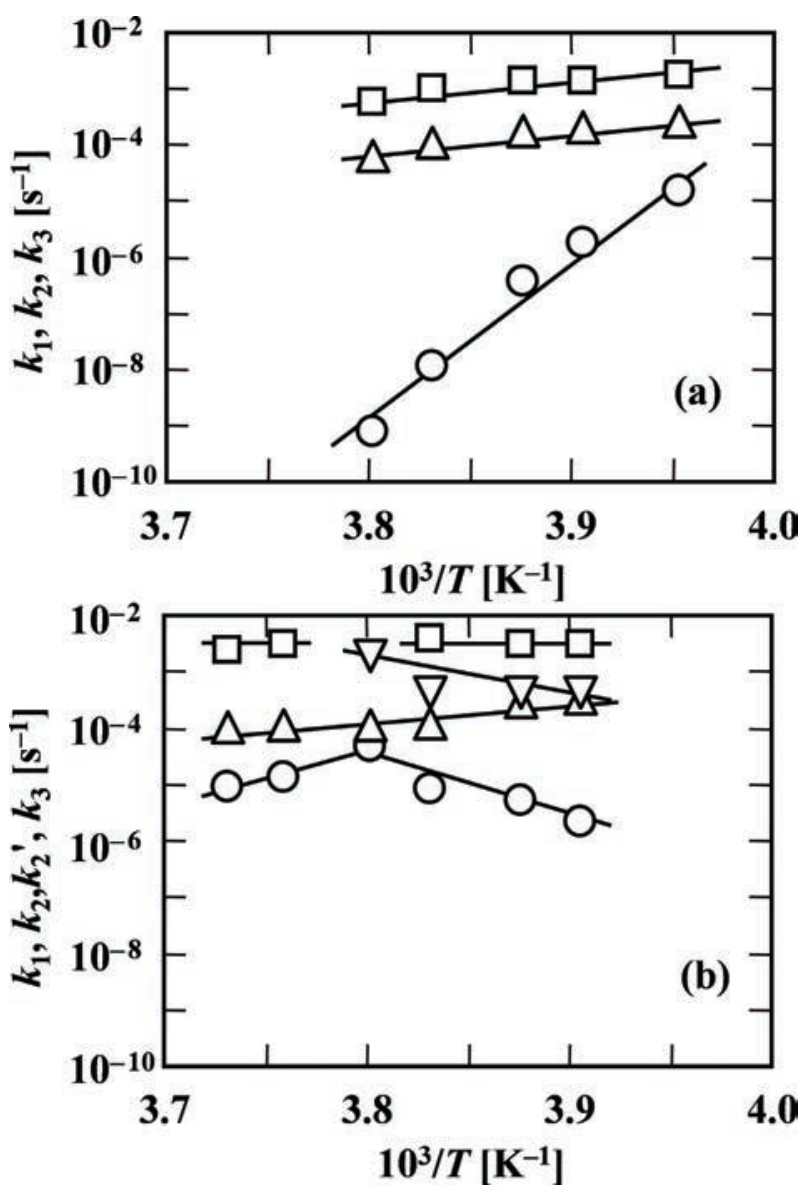

FIGURE 8. Arrhenius plots of the rate constants for the crystallization of (a) safflower and (b) olive oils.

The fact that no temporary increase in transmitted light intensity was observed at $-10{ }^{\circ} \mathrm{C}$ may seem to contradict the progress of step $2^{\prime}$. However, it is reasonable from the discussion on the changes in volume and density to understand that the crystallization behavior varies below $-10^{\circ} \mathrm{C}$. At $-10^{\circ} \mathrm{C}$, the temporary change in transmitted light intensity may not be observed owing to the great influence of the volumetric change in step $2^{\prime}$. At $-12^{\circ} \mathrm{C}$ or lower, because the $k_{2}^{\prime}$ became small and it was difficult for step $2^{\prime}$ to proceed, step 3 would have proceeded significantly. It is considered that step 2 became dominant as the temperature decreased and that step 1 became inferior to decrease the $k_{1}$ value. The behaviors of the volume decreases in safflower and olive oils could be explained by the same kinetic model as that used for rapeseed oil, suggesting that the crystallization mechanism of these three oils would be the same. Focusing on the relationships between the magnitude of each rate constant and the storage temperature, the $k_{2}, k_{2}^{\prime}$, and $k_{3}$ values were almost common for safflower, olive and rapeseed oils. The temperature dependences of the $k_{2}$ and $k_{3}$ values were both small, and the decrease in $k_{2}{ }^{\prime}$ 
with the decrease in storage temperature was similar among the three oils. Because the $k_{1}$ value depends largely on the oil type, it is expected to be a parameter which characterizes oil crystallization.

The fatty acids and TAG compositions of the oils depend on their growing area and variety. However, since their main components do not change greatly, the results on the induction period and the rate constants for crystallization obtained in this study may be helpful in roughly predicting the crystallization behaviors of safflower and olive oils. They would be useful in developing efficient purification methods for safflower and olive oils and in determining the appropriate preservation conditions of foods which contain these oils.

\section{CONCLUSIONS}

Changes in volume and transmitted light intensity of safflower and olive oils were measured during storage at $-10,-12,-15,-17$, and $-20{ }^{\circ} \mathrm{C}$ and at $-5,-7,-10,-12,-15$, and $-17{ }^{\circ} \mathrm{C}$, respectively. The behaviors of volume and transmitted light intensity with time for safflower oil gradually changed with a decrease in storage temperature. On the contrary, those for olive oil were entirely different above and below $-10^{\circ} \mathrm{C}$. It was suggested that the crystallization behaviors of safflower and olive oils such as changes in volume and transmitted light intensity can differ depending on the occurrence of the transition. The transition would be affected by minor components with high melting points. The volumetric changes in the safflower and olive oils with time were analyzed based on a kinetic model proposed in a previous study for rapeseed oil crystallization. The kinetic model reasonably represented the volumetric changes in the safflower and olive oils, although the apparent behaviors were significantly different. It is suggested that the crystallization mechanism of vegetable oil is essentially the same even though the crystallization behavior appears to be different.

\section{ACKNOWLEDGMENTS}

This study was supported by Grant-in-Aid for JSPS Fellows (Y.M.), JSPS KAKENHI Grant Number JP18J01966.

\section{REFERENCES}

Abeshima T. 1998. Fractionation of edible oils and fats. $J$. Jpn. Oil Chem. Soc. 47, 553-561. https://doi.org/10.5650/ jos1996.47.553

Avrami M. 1940. Kinetics of phase change. II transformationtime relations for random distribution of nuclei. J. Chem. Phys. 8, 212-224. https://doi.org/10.1063/1.1750631

Bailey AE, Kraemer EA. 1944. Dilatometric investigations of fats I. Apparatus and techniques for fat dilatometry. Oil Soap 21, 251-253. https://doi.org/10.1007/BF02565466
Bayés-García L, Calvet T, Cuevas-Diarte MA, Ueno S. 2017. From trioleoyl glycerol to extra virgin olive oil through multicomponent triacylglycerol mixtures: Crystallization and polymorphic transformation examined with differential scanning calorimetry and X-ray diffration techniques. Food Res. Int. 99, 475-484. https://doi.org/10.1016/j. foodres.2017.06.015

Calligaris S, Arrighetti G, Barba L, Nicoli MC. 2008. Phase transition of sunflower oil as affected the oxidation level. J. Am. Oil Chem. Soc. 85, 591-598. https://doi.org/10.1007/ s11746-008-1241-y

Calligaris S, Sovrano S, Manzocco L, Nicoli MC. 2006. Influence of crystallization on the oxidative stability of extra virgin olive oil. J. Agric. Food Chem. 54, 529-535. https://doi. org/10.1021/jf051808b

Campbell SD, Goff HD, Rousseau D. 2004. Modeling the nucleation and crystallization kinetics of a palm stearin/ canola oil blend and lard in bulk and emulsified form. $J$. Am. Oil Chem. Soc. 81, 213-219. https://doi.org/10.1007/ s11746-004-0884-9

Chiavaro E, Cerretani L, Paciulli M, and Vecchio S. 2012. Kinetic evaluation of non-isotermal crystallization of oxidized extra virgin olive oil. J. Therm. Anal. Calorium. 108, 799-806. https://doi.org/10.1007/s10973-011-2083-7

Coupland JN. 2002. Crystallization in emulsions. Curr. Opin. Colloid Interface Sci. 7, 445-450. https://doi.org/10.1016/ S1359-0294(02)00080-8

Fujiwara M, Iwanaga Y, Yoshida H. 1972. Processing of edible oil and fat product. J. Jpn. Oil Chem. Soc. 21, 670-675. https://doi.org/10.5650/jos1956.21.670

Fulton ND, Lutton ES, Wille RL. 1954. A quick dilatometric method for control and study of plastic fats. J. Am. Oil Chem. Soc. 31, 98-103. https://doi.org/10.1007/ BF02612492

Hamm W. 1995. Trends in edible oil fractionation. Trends Food Sci. Technol. 6, 121-126. https://doi.org/10.1016/ S0924-2244(00)88995-5

Himawan C, Starov VM, Stapley AGF. 2006. Thermodynamic and kinetic aspects of fat crystallization. Adv. Colloid Interface Sci. 122, 3-33. https://doi.org/10.1016/j. cis. 2006.06 .016

Kellens M, Meeussen W, Reynaers H. 1992. Study of the polymorphism and the crystallization kinetics of tripalmitin: a microscopic approach. J. Am. Oil Chem. Soc. 69, 906-911. https://doi.org/10.1007/BF02636342

MacNaughtan W, Farhat IA, Himawan C, Starov VM, Stapley AGF. 2006. A differential scanning calorimetry study of the crystallization kinetics of tristearin-tripalmitin mixtures. J. Am. Oil Chem. Soc. 83, 1-9. https://doi.org/10.1007/ s11746-006-1167-1

Miyagawa Y, Ogawa T, Nakagawa K, Adachi S. 2016. Destabilization of mayonnaise induced by lipid crystallization upon freezing. Biosci. Biotechnol. Biochem. 80, 786-790. https://doi.org/10.1080/09168451.2015.1123611

Miyagawa Y, Ogawa T, Nakagawa K, Adachi S. 2015. Effects of vegetable oil type and lipophilic emulsifiers on the induction period of fat crystallization. J. Oleo Sci. 64, 1169-1174. https://doi.org/10.5650/jos.ess 15170

Miyagawa Y, Shintani K, Katsuki K, Nakagawa K, Adachi S. 2017. Thermal and structural changes of rapeseed oil during isothermal storage at low temperature. Food Structure 11, 8-15. https://doi.org/10.1016/j.foostr.2016.12.004

Miyagawa Y, Yoshida M, Chizawa Y, Adachi S. 2019. Induction periods for lipid crystallization of various vegetable oils. $J$. Oleo Sci. in print.

Miyagawa Y, Yoshida M, Nakagawa K, Adachi S. 2018. Kinetic analysis of rapeseed oil crystallization during isothermal storage. Cryst. Growth Des. 18, 642-650. https://doi. org/10.1021/acs.cgd.7b00789

Oliveira GM de, Ribeiro APB, Santos AO dos, Cardoso LP, Kieckbusch TG. 2015. Hard fats as additives in palm oil and its relationships to crystallization process and polymorphism. LWT-Food Sci. Technol. 63, 1163-1170. https://doi.org/10.1016/j.lwt.2015.04.036

Quast LB, Luccas V, Ribeiro APB, Cardoso LP, Kieckbusch TG. 2013. Physical properties of tempered mixtures of cocoa 
$10 \bullet$ M. Yoshida et al.

butter, CBR and CBS fats. Int. J. Food Sci. Technol. 48, 1579-1588. https://doi.org/10.1111/ijfs.12127.

Rincón-Cardona JA, Martini S, Candal RJ, Herrera ML. 2013. Polymorphic behavior during isothermal crystallization of high stearic high oleic sunflower oil stearins. Food Res. Int. 51, 86-97. https://doi.org/10.1016/j.foodres. 2012.11.023

Rousseau D. 2000. Fat crystals and emulsion stability-a review. Food Res. Int. 33, 3-14. https://doi.org/10.1016/ S0963-9969(00)00017-X

Timms RE. 1985. Physical properties of oils and mixtures of oils. J. Am. Oil Chem. Soc. 62, 241-249. https://doi.org/10.1007/ BF02541385
Totani Y. 2012. Characteristic of fat and oil, and its application. Saiwaisyobo, Tokyo, Japan.

Turnbull D, Fisher JC. 1949. Rate of nucleation in condensed systems. J. Chem. Phys. 17, 71-73. https://doi. org/10.1063/1.1747055

Wright AJ, Narine SS, Marangoni AG. 2000. Comparison of experimental techniques used in lipid crystallization studies. J. Am. Oil Chem. Soc. 77, 1239-1242. https://doi. org/10.1007/s11746-000-0194-2

Yoshikawa S, Kida H, Matsumura Y, Sato K. 2016. Adding talc particles improves physical properties of palm oil-based shortening. Eur. J. Lipid Sci. Technol. 118, 1007-1017. https://doi.org/10.1002/ejlt.201500283 